\title{
Environmental Factors Identified in the Etiology of Oral Cancers in Taiwan
}

\author{
Chi-Ting Chiang1, \\ Che-Chun Su${ }^{4}$, Kuo-Yang Tsai ${ }^{5}$ and Yaw-Huei Hwang 6 \\ ${ }^{1}$ Green Energy and Environment Research Laboratories, \\ Industrial Technology Research Institute, \\ ${ }^{2}$ Department of Bioenvironmental Systems Engineering, National Taiwan University, \\ ${ }^{3}$ Graduate Institute of Statistics and Information Science, \\ National Changhua University of Education, \\ ${ }^{4}$ Department of Internal Medicine, Changhua Christian Hospital, \\ ${ }^{5}$ Department of Oral and Maxillofacial Surgery, Changhua Christian Hospital, \\ ${ }^{6}$ Department of Public Health, National Taiwan University
} Taiwan

\section{Introduction}

There is an extensive variation in the incidence and mortality rates of oral cancer in different regions and countries of the world. While oral cancer is predominantly prevalent in South Asia and Southeast Asia, countries such as India, Pakistan, Bangladesh and Taiwan also have persistently increasing trends in incidence rates (Reichart \& Way, 2006). Oral cancer is much more predominant in Taiwanese males than in females and the prevalence in male peaks at age between 45 and 65 years old. A review of the Taiwan Cancer Registry Database (TCRD) shows that the mortality rate for oral cancer ranked the fourth among the top 10 leading causes of cancer death in Taiwan since 2003 (Bureau of Health Promotion [BHP], 2011a). In Taiwan, the oral cancer incidence rate in male grew by nearly $22.1 \%$ in 2008 , with comparative figures for 1995 (BHP, 2011a). Between 1997 and 2007, the number of oral cancer cases per year grew from 2,795 to 5,458 , representing an increase of $119 \%$; the number of deaths due to oral cancer jumped from 1,163 cases to 2,312 cases per year, representing an increase of 99\% (BHP, 2011b). In addition, according to the statistical report from the Department of Health of the Executive Yuan, young and middle-aged Taiwanese males (between the ages of 25 and 44) are most likely to develop oral cancer. It is even more worrisome to note that the trend in the age of oral cancer has tended towards decreased age-groups in Taiwan on a yearly basis in recent years. Oral cancer has recently become a notable public health concern in Taiwan. Therefore, from a public health perspective, it is important and imperative to study the clinical and epidemiologic characteristics of oral cancer in Taiwan.

The development of various types of cancer is very complex and is influenced by many risk factors including hereditary, socio-demographics (such as age, gender, ethnicity, level of education, etc.), lifestyle, and environmental factors. The International Agency for Research

${ }^{*}$ Corresponding Author 
on Cancer (IARC) has identified intake of alcoholic beverages (AB), betel quid chewing (BQC) with tobacco, and cigarette smoking (CS) as human carcinogens, with the target organs including the oral cavity, pharynx, larynx and oesophagus (IARC, 1988, 2003). So far, results of numerous studies have demonstrated that BQC, CS, and $\mathrm{AB}$ clearly relate to the development of oral cancer, and are therefore the major etiological factors for oral cancer, (Blot et al., 1988; Cancela et al., 2009; Choi \& Kahyo, 1991; Merletti et al., 1989; Ogden, 2005; Petti \& Scully, 2005). In a case-control study carried out in Taiwan, the probability of oral cancer in patients who consumed tobacco, alcohol and betel quid was 123-fold higher than that of abstainers, indicating that these three activities act synergistically (Ko et al., 1995). In Taiwan, BQC is much strongly correlated to oral cancer among these three factors; however, as BQC and CS normally coexist, the effects of BQC on human health in Taiwan can hardly be distinguished from the integrated effects of both (Wen et al., 2005). Oral cancer is a male dominant disease amongst the Taiwanese; a finding consistent with the prevalence rate of $\mathrm{BQC}$ is much higher in males than in females in that population. Among Taiwanese aborigines, betel quid is frequently used in traditional festivals, ceremonial rituals as well as daily life in line with custom. In consequence, the aboriginal population in Taiwan has a relatively higher risk for oral cancer than the Han Chinese.

Annual age-standardized incidence rate (ASIR) for oral cancer for the 22 counties in Taiwan Island indicated that two regions in the eastern (Taitung and Hualien Counties) and in the middle (Changhua and Yunlin Counties) Taiwan have very high incidence than the other regions. Table 1 shows that from 1995 to 2008, the 14-year average incidence rates of oral cancer in males in Taitung, Hualien, Changhua, and Yunlin Counties were 43.6, 36.0, 42.6, and 41.5 cases per 100,000 person-years, respectively, which were higher than that for the rest of the 18 counties (24.0 cases per 100,000 person-years). Thus, these four counties are "hot spots" of oral cancer in Taiwan. Although the prevalence of BQC use in Taiwan has declined in the middle (18.3\% to $9.3 \%)$ and the eastern $(44.0 \%$ to $36.6 \%)$ parts of Taiwan (44.0\% to 36.6\%) between 1996 and 2002 (Yang et al., 2002), oral cancer incidence rates have been rising rapidly in the past several decades (Su et al., 2007). However, a dramatically distinct difference in male-to-female ratio for oral cancer incidence appears between these two areas, i.e. the middle and eastern Taiwan (Table 1). As shown in Table 2, a large proportion of the aboriginal population residing in both Hualien and Taitung Counties, the home of the aboriginal people, have a high incidence of oral cancer, and the prevalence rates for the use of BQC and CS in males and females are equally high(Table 3). In contrast, Changhua and Yunlin Counties have only a small proportion of aboriginal population living in them (Table 2). As can be seen in Table 1 3, Changhua County in particular belongs to a high-risk oral cancer area and has the abnormally high male-to-female ratio of oral cancer incidence in spite of the fact that that its BQC and CS activities are only moderately high among the 22 county regions. Based on the above discussion, these known major risk factors for oral cancer (BQC/CS prevalence and ethnicity) do not fully explain the geographical occurrence of oral cancer "hot spots" in Taiwan. Therefore, there may be other potential risk factors such as genetics, lifestyle, and environmental, yet unknown that influence the development of oral cancer among these population.

It is estimated that as many as two-thirds of all cancer cases are linked to environmental causes (National Cancer Institute \& National Institute of Environmental Health Sciences [NCI \& NIEHS], 2003). Industrialization and urbanization in Taiwan over the past two 
decades have chronically polluted a huge amount of farm soil due to the discharge of industrial wastewater into the irrigation systems. Moreover, according to the nationwide systematic survey of farm soil conducted by the Environmental Protection Administration (EPA) in Taiwan, Changhua County is known as the granary of Taiwan, where farm soil has been seriously polluted by heavy metals. Environmental factor is suspected to play a critical role in the process of developing oral cancer in Taiwan.

\begin{tabular}{|c|c|c|c|c|c|c|c|c|c|c|}
\hline \multirow{3}{*}{ Year } & \multicolumn{4}{|c|}{ Middle Taiwan } & \multicolumn{4}{|c|}{ Eastern Taiwan } & \multirow{2}{*}{\multicolumn{2}{|c|}{ Others }} \\
\hline & \multicolumn{2}{|c|}{ Changhua } & \multicolumn{2}{|c|}{ Yunlin } & \multicolumn{2}{|c|}{ Taitung } & \multicolumn{2}{|c|}{ Hualien } & & \\
\hline & Male & Female & Male & Female & Male & Female & Male & Female & Male & Female \\
\hline 1995 & 28.4 & 2.5 & 22.6 & 1.7 & 25.6 & 7.9 & 13.7 & 4.3 & 13.3 & 1.6 \\
\hline 1996 & 30.1 & 2.5 & 25.6 & 1.1 & 30.6 & 9.9 & 29.0 & 4.2 & 14.3 & 2.0 \\
\hline 1997 & 31.2 & 2.0 & 36.3 & 1.7 & 32.5 & 13.9 & 23.1 & 7.1 & 16.7 & 2.0 \\
\hline 1998 & 36.9 & 1.8 & 29.9 & 4.0 & 34.0 & 4.6 & 28.4 & 5.6 & 19.4 & 2.1 \\
\hline 1999 & 40.7 & 1.8 & 37.9 & 3.7 & 41.2 & 7.2 & 35.0 & 5.7 & 20.7 & 2.3 \\
\hline 2000 & 40.7 & 2.5 & 37.0 & 3.2 & 39.5 & 5.9 & 36.1 & 5.1 & 22.9 & 2.1 \\
\hline 2001 & 41.4 & 2.2 & 38.4 & 2.8 & 37.6 & 14.5 & 24.6 & 6.7 & 23.3 & 2.5 \\
\hline 2002 & 40.7 & 3.6 & 36.7 & 1.9 & 42.8 & 8.0 & 34.7 & 3.6 & 23.7 & 2.7 \\
\hline 2003 & 46.5 & 3.3 & 55.8 & 4.1 & 61.0 & 14.5 & 41.2 & 6.0 & 27.3 & 2.6 \\
\hline 2004 & 51.9 & 3.1 & 54.0 & 3.5 & 52.2 & 11.8 & 46.9 & 6.4 & 28.9 & 3.0 \\
\hline 2005 & 48.0 & 2.9 & 51.4 & 2.6 & 50.5 & 12.2 & 42.1 & 7.5 & 29.2 & 2.8 \\
\hline 2006 & 52.7 & 3.6 & 60.1 & 3.3 & 62.6 & 12.9 & 51.8 & 9.1 & 31.5 & 2.9 \\
\hline 2007 & 52.4 & 3.0 & 47.8 & 4.1 & 44.6 & 8.7 & 48.8 & 5.5 & 31.9 & 2.7 \\
\hline 2008 & 55.1 & 1.8 & 47.9 & 1.3 & 56.3 & 13.9 & 48.6 & 8.4 & 33.0 & 2.6 \\
\hline Average & 42.6 & 2.6 & 41.5 & 2.8 & 43.6 & 10.4 & 36.0 & 6.1 & 24.0 & 2.4 \\
\hline Ratio & & 7.1 & 16 & 6.8 & & 4.5 & & 6.1 & & .8 \\
\hline
\end{tabular}

Table 1. Annual age-standardized incidence rate (ASIR) of oral cancer and average male-tofemale ratios of oral cancer incidence in middle and eastern Taiwan and the rest of the counties, 1995-2008. 
Heavy metals are extremely persistent in the environment and can cause adverse effects on human health. Many metals, including arsenic (As), chromium (Cr[VI]), and nickel (Ni[II]), have been classified as human carcinogens (International Agency for Research on Cancer [IARC], 1987, 1990). Consequently, long-term exposure to heavy metals in the air, water, and soil may increase the risk of a certain type of human cancer. Previous studies have also found that the high content of soil heavy metals in the region had high incidence or mortality rates of several types of cancers, such as stomach, prostate, bladder, esophageal, and gastrointestinal cancers (Rheeder et al., 1994; Stocks \& Davies, 1964; Türkdoğan et al., 2003). These findings indirectly suggested a possible link between local residents' exposure to heavy metals in soil and the incidence of cancer. Soil and the human body both intake environmental heavy metals, which can be absorbed through various ways. That is to say, soil and the human body are both recipients of environmental pollutants. Thus, the content of heavy metals in soil is an index of possible environmental exposure to heavy metal, and it can also slightly reflect the extent of the potential exposure on the human body in the living environment. In addition to socio-demographic factor (i.e. the ethnic distribution) and lifestyle factors (i.e. the prevalence of BQC and CS), the content of soil heavy metals as a environmental factor is to explore the association between oral cancer occurrence and heavy metal pollution in the environment in Taiwan.

The development of geographic information systems (GIS) has offered a more powerful and efficient ability to visually inspect the spatial patterns and processes over the last twenty years. On the other hand, many recent epidemiological studies have widely used spatial analyses to identify possible causes related to the occurrence or outbreak of various diseases. A wide variety of statistical techniques to detect and describe spatial and temporal clustering have been applied in a range of disciplines, including geography, ecology, econometrics, biostatistics and medicine (Ward \& Carpenter, 2000). Investigation of potential clustering of disease occurrence is a foundation of epidemiology, which provides valuable information on possible causes of the disease of interest and methods that may be used for disease control and prevention (Ward \& Carpenter, 2000). Constructing diseasespecific maps to depict geo-referencing health data cartographically can facilitate the identification of possible causes of disease as well as provide an additional perspective on clinical medicine, epidemiological studies and health improvement (Chiang et al., 2010). In this way, GIS, when combined with spatial analytical methods, may be assisted in the study of healthcare issues. Kitron \& Kazmierczak (1997) indicated that counties with most human cases and tick were clustered in parts of western Wisconsin by using a measure of spatial autocorrelation. Pfeiffer et al. (2007) used a spatial clustering method to identify a sequence of three epidemic waves of highly pathogenic avian influenza (HPAI) occurred in Vietnam during the time period 2004-2006. Additionally, spatial regression analysis quantifies the spatial pattern through creating a specific-contiguity weight and examining the relationship between the attributes of interest and latent explanatory variables that can interpret the observed spatial pattern (Zeng et al., 2008). Green et al. (2003) identified the geographical location of Diabetes Mellitus (DM) clusters in the City of Winnipeg in Canada, and indicated high rates of DM prevalence are strongly correlated with some risk factor indicators by the combination of both spatial clustering and spatial regression methods.

In this chapter, we used GIS and Moran-based spatial statistics to associate the townshiplevel oral cancer mortality rates with the prevalence of $\mathrm{BQC}$ and CS, the distribution of 
aboriginal population, and the content of soil heavy metals. The purpose was to identify the geographical locations of "hot spots" of various surveillance variables over the entire township of Taiwan, and then to determine and explain the magnitude of spatial association among these surveillance variables.

\begin{tabular}{|c|c|c|c|c|c|c|c|c|c|c|c|}
\hline $\begin{array}{l}\text { County } \\
\text { regions }\end{array}$ & 2000 & 2001 & 2002 & 2003 & 2004 & 2005 & 2006 & 2007 & 2008 & 2009 & Average \\
\hline Hualien & 20.6 & 20.2 & 20.0 & 19.7 & 19.5 & 19.1 & 18.8 & 18.5 & 18.2 & 18.0 & 19.3 \\
\hline Taitung & 18.8 & 18.4 & 18.1 & 17.7 & 17.3 & 17.0 & 16.7 & 16.3 & 16.0 & 15.9 & 17.2 \\
\hline Pingtung & 12.5 & 12.5 & 12.3 & 12.1 & 11.9 & 11.8 & 11.7 & 11.5 & 11.4 & 11.3 & 11.9 \\
\hline Taoyuan & 9.2 & 9.3 & 9.5 & 9.8 & 10.1 & 10.4 & 10.8 & 11.1 & 11.3 & 11.4 & 10.3 \\
\hline Taipei & 7.6 & 7.8 & 7.9 & 8.1 & 8.4 & 8.6 & 8.8 & 9.1 & 9.3 & 9.4 & 8.5 \\
\hline Nantou & 6.0 & 6.0 & 6.0 & 5.9 & 5.9 & 5.8 & 5.7 & 5.7 & 5.6 & 5.6 & 5.8 \\
\hline Hsinchu & 3.9 & 3.9 & 3.9 & 3.8 & 3.8 & 3.8 & 3.8 & 3.8 & 3.8 & 3.8 & 3.8 \\
\hline Taichung & 3.3 & 3.4 & 3.4 & 3.5 & 3.6 & 3.7 & 3.7 & 3.8 & 3.9 & 3.9 & 3.6 \\
\hline Kaohsiung & 3.3 & 3.4 & 3.3 & 3.4 & 3.3 & 3.4 & 3.4 & 3.4 & 3.4 & 3.4 & 3.4 \\
\hline Ilan & 3.0 & 3.0 & 3.0 & 3.0 & 3.0 & 3.0 & 3.0 & 3.0 & 3.0 & 3.0 & 3.0 \\
\hline Taipei City & 2.1 & 2.2 & 2.4 & 2.4 & 2.4 & 2.5 & 2.5 & 2.6 & 2.6 & 2.6 & 2.4 \\
\hline Miaoli & 2.1 & 2.1 & 2.0 & 2.0 & 2.0 & 2.0 & 2.0 & 2.0 & 2.1 & 2.1 & 2.1 \\
\hline Kaohsiung City & 1.8 & 1.8 & 1.9 & 2.0 & 2.1 & 2.1 & 2.1 & 2.2 & 2.2 & 2.3 & 2.0 \\
\hline Keelung City & 1.6 & 1.6 & 1.6 & 1.6 & 1.6 & 1.7 & 1.7 & 1.7 & 1.7 & 1.7 & 1.7 \\
\hline Taichung City & 1.0 & 1.1 & 1.1 & 1.2 & 1.2 & 1.3 & 1.3 & 1.4 & 1.4 & 1.4 & 1.2 \\
\hline Chiayi & 1.1 & 1.1 & 1.1 & 1.1 & 1.1 & 1.1 & 1.1 & 1.1 & 1.1 & 1.1 & 1.1 \\
\hline Changhua* & 0.7 & 0.7 & 0.7 & 0.8 & 0.9 & 0.9 & 0.9 & 0.9 & 0.9 & 0.9 & 0.8 \\
\hline Tainan & 0.5 & 0.5 & 0.5 & 0.6 & 0.6 & 0.6 & 0.7 & 0.7 & 0.7 & 0.7 & 0.6 \\
\hline Hsinchu City & 0.4 & 0.4 & 0.4 & 0.4 & 0.4 & 0.5 & 0.5 & 0.5 & 0.5 & 0.6 & 0.5 \\
\hline Tainan City & 0.2 & 0.2 & 0.3 & 0.3 & 0.3 & 0.3 & 0.3 & 0.4 & 0.4 & 0.4 & 0.3 \\
\hline Yunlin* & 0.2 & 0.2 & 0.2 & 0.3 & 0.3 & 0.3 & 0.3 & 0.3 & 0.3 & 0.3 & 0.3 \\
\hline Chiayi City & 0.1 & 0.1 & 0.1 & 0.1 & 0.2 & 0.2 & 0.2 & 0.2 & 0.2 & 0.2 & 0.2 \\
\hline
\end{tabular}

Table 2. The proportion of the aboriginal population in each county region throughout the Taiwan Island, 2000-2009.

The proportion is equal to the number of aboriginal population in county divided by the total number of aboriginal population throughout Taiwan Island. 


\begin{tabular}{|c|c|c|c|c|c|c|}
\hline \multirow{2}{*}{$\begin{array}{l}\text { County } \\
\text { regions }\end{array}$} & \multicolumn{3}{|c|}{ BQC prevalence $(\%)$} & \multicolumn{3}{|c|}{ CS prevalence (\%) } \\
\hline & All & Male & Female & All & Male & Female \\
\hline Taitung & $24.4(1)$ & $30.0(2)$ & $18.0(1)$ & $14.4(1)$ & $47.4(2)$ & $14.4(1)$ \\
\hline Hualien & $21.6(2)$ & $32.6(1)$ & $9.6(2)$ & $13.4(2)$ & $46.0(5)$ & $13.4(2)$ \\
\hline Pingtung & $16.0(3)$ & $26.1(3)$ & $5.1(3)$ & $4.2(15)$ & $48.1(1)$ & $4.2(15)$ \\
\hline Yunlin & $13.4(4)$ & $24.8(4)$ & $0.5(10)$ & $5.1(9)$ & $43.4(7)$ & $5.1(9)$ \\
\hline Chiayi & $13.0(5)$ & $24.0(5)$ & $0.6(7)$ & $5.1(9)$ & $42.4(10)$ & $5.1(9)$ \\
\hline Nantou & $12.9(6)$ & $23.7(6)$ & $1.2(4)$ & $6.3(6)$ & $46.3(4)$ & $6.3(6)$ \\
\hline Tainan & $9.5(7)$ & $18.1(7)$ & $0.4(12)$ & $4.1(16)$ & $43.6(6)$ & $4.1(16)$ \\
\hline Miaoli & $9.2(8)$ & $17.3(8)$ & $0.0(20)$ & $3.1(20)$ & $42.3(11)$ & $3.1(20)$ \\
\hline Taichung & $8.4(9)$ & $15.9(9)$ & $0.6(7)$ & $4.4(14)$ & $41.6(13)$ & $4.4(14)$ \\
\hline Kaohsiung & $8.4(10)$ & $15.7(10)$ & $0.7(6)$ & $5.0(12)$ & $42.8(9)$ & $5.0(12)$ \\
\hline Ilan & $8.1(11)$ & $15.2(11)$ & $0.5(10)$ & $4.5(13)$ & $42.9(8)$ & $4.5(13)$ \\
\hline Taoyuan & $7.7(12)$ & $14.7(12)$ & $0.6(7)$ & $6.6(5)$ & $41.5(14)$ & $6.6(5)$ \\
\hline Changhua* & $7.3(13)$ & $14.1(13)$ & $0.1(18)$ & $2.9(21)$ & $36.3(20)$ & $2.9(21)$ \\
\hline Chiayi City & $7.1(14)$ & $14.0(14)$ & $0.2(17)$ & $3.7(18)$ & $39.8(16)$ & $3.7(18)$ \\
\hline Tainan City & $6.3(15)$ & $12.6(15)$ & $0.0(20)$ & $2.0(22)$ & $36.2(21)$ & $2.0(22)$ \\
\hline Keelung & $6.2(16)$ & $12.0(16)$ & $0.3(15)$ & $6.7(4)$ & $46.5(3)$ & $6.7(4)$ \\
\hline Hsinchu & $5.8(17)$ & $10.4(20)$ & $0.8(5)$ & $4.1(16)$ & $39.8(16)$ & $4.1(16)$ \\
\hline Hsinchu City & $5.4(18)$ & $10.7(17)$ & $0.0(20)$ & $5.2(8)$ & $40.4(15)$ & $5.2(8)$ \\
\hline Taipei & $5.4(18)$ & $10.6(18)$ & $0.3(15)$ & $5.3(7)$ & $41.9(12)$ & $5.3(7)$ \\
\hline Taichung City & $5.3(20)$ & $10.5(19)$ & $0.4(12)$ & $6.8(3)$ & $39.0(18)$ & $6.8(3)$ \\
\hline Kaohsiung City & $5.0(21)$ & $9.5(21)$ & $0.4(12)$ & $3.6(19)$ & $36.9(19)$ & $3.6(19)$ \\
\hline Taipei City & $2.6(22)$ & $5.4(22)$ & $0.0(20)$ & $5.1(9)$ & $32.1(22)$ & $5.1(9)$ \\
\hline
\end{tabular}

Numbers in parentheses indicate the ranks of the prevalence rates among the 22 county regions.

Table 3. The prevalence rates of BQC and CS in each county region throughout the Taiwan Island in 2005 (BHP, 2011c).

\section{Materials and methods}

\subsection{Study area}

This study was conducted mainly in Taiwan Island. Taiwan locates in the heart of the Festoon Islands at the west coast of Pacific Ocean, and it plays a vital and indispensable role as a key transport hub in the East Asian region. The political geography of Taiwan can be divided into four major regions as follows: the north, middle, south, and east regions, as 
shown in Fig. 1. The total area of Taiwan Island is about 36,000 square kilometres with a population of about 23 million, and a population density of 640 persons per square kilometres. Taiwan's population has grown very rapidly in a very short time. Taiwan is also becoming an increasingly dominating urban society with its population almost concentrated on the northern and southern of Taiwan Island, in two metropolitan cities of Taipei and Kaohsiung. The majority of ethnic groups in Taiwan are Han Chinese and aboriginal, whose proportions are $97.8 \%$ and $2.2 \%$ respectively. The latter live primarily in the eastern valleys and central mountainous areas (Lin et al., 2008). Over the past three decades, Taiwan's industry has transformed from early agriculture to manufacture (industrialization), and then from manufacture to high-tech innovation (knowledge work). In 1995, the compulsory health care delivery system in Taiwan, called the National Health Insurance (NHI), was implemented with an emphasis on equal access to health care, regardless of socioeconomic status.

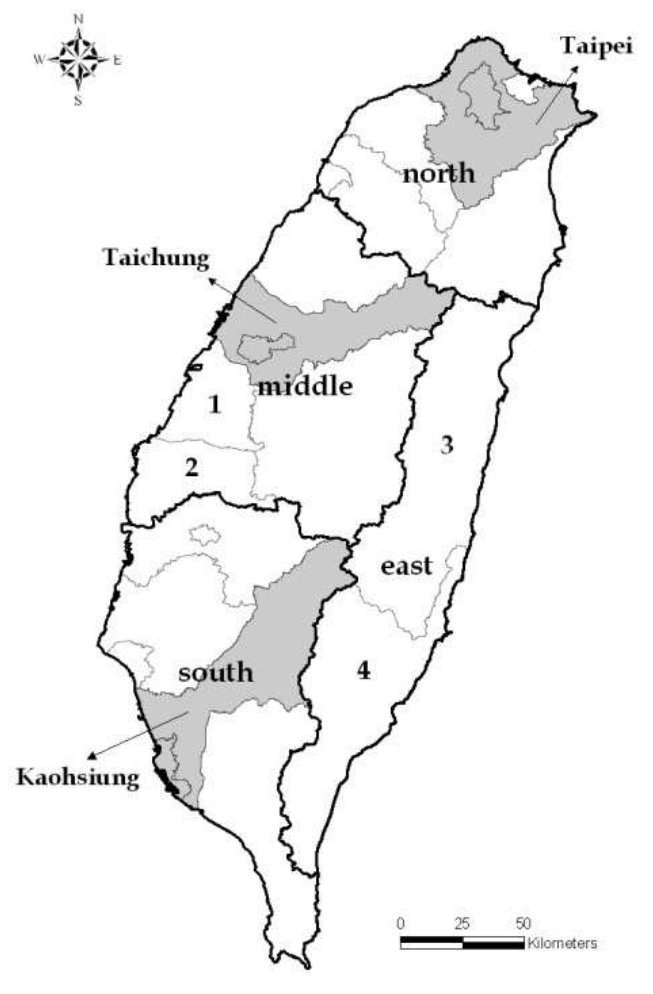

Fig. 1. Four major geographic regions of Taiwan. 1) Changhua County, 2) Yunlin County, 3) Hualien County, 4) Taitung County. 


\subsection{Data on oral cancer mortality rates}

Taiwan established its comprehensive national cancer registry and database in 1979. Data on oral cancer mortality rates were obtained from the Atlas of Cancer Mortality in Taiwan constructed in 2003 by Taiwan's Department of Health (DOH), which contains agestandardized mortality rates (ASMR) in both genders of each township for each decade from 1972 to 2001. Additionally, data on ASMR of oral cancer in male and all gender (i.e. male plus female) for each township from 2001 to 2009 were obtained from the statistical reports on the leading cause of cancer death, which were also provided by Taiwan's DOH. Each township was treated as a unit in the analysis in this study.

\subsection{Data on aboriginal population}

In this study, a principal source of demographic data for the aboriginal population is the census. There are several culturally and ethno-linguistically distinct aboriginal tribes in Taiwan, who live mainly in the eastern plains and central mountains. In total, the Taiwanese aboriginal tribes consist of about 500,000 people. Data on aboriginal population of each township across Taiwan Island from 1998 to 2010 were retrieved from the Department of Household Registration Affairs.

\subsection{Data on known risk habits of oral cancer}

The prevalence rates of BQC and CS were estimated from the National Health Interview Survey (NHIS) data in 2002, which was conducted cooperatively by the National Health Research Institutes (NHRI) and Taiwan's DOH. The survey subjects included 1,086 males and 1,473 females from all over Taiwan Island. However, only data from males and all gender were considered in calculation due to the low rates of BQC and CS among females. Similarly, data on the prevalence rates of BQC and CS were studied based on the township level.

\subsection{Data on the content of soil heavy metals}

Soil data in this study were derived from a progressive, nationwide survey that determined the concentration in agricultural topsoil $(0-15 \mathrm{~cm})$ of arsenic (As), cadmium $(\mathrm{Cd})$, chromium $(\mathrm{Cr})$, copper $(\mathrm{Cu})$, mercury $(\mathrm{Hg})$, nickel $(\mathrm{Ni})$, lead $(\mathrm{Pb})$ and zinc $(\mathrm{Zn})$, conducted by the Environmental Protection Administration (EPA) in Taiwan from 1986 to 1990 (Environmental Protection Administration, R.O.C. (Taiwan) [ROCEPA], 1985). The total concentration of extractable $\mathrm{As}$ and $\mathrm{Hg}$ in the soil was determined by the aqua regia method, as well as the other six heavy metals by the $0.1 \mathrm{~N} \mathrm{HCl}$ extraction method. A grid cell size of 1,600 ha was used as sampling unit and 936 soil samples were collected across Taiwan Island. The area-weighted mean value represented the soil heavy metal content in each township.

\subsection{Principal component analysis}

Principal component analysis (PCA) is an exploratory data analysis tool introduced in 1901 by Karl Pearson (Pearson, 1901), and later on extended in 1933 by Harold Hotelling 
(Hotelling, 1933). PCA is a linear eigenvector-based dimensionality reduction technique, which is based on orthogonal transforming a large set of potentially correlated variables into a new and smaller subset of uncorrelated variables with maximum variance. These new variables, called principal components (PCs), are obtained as linear combinations of the original variables. The number of $\mathrm{PC}$ is less than or equal to the number of original variables $(\mathrm{q} \leqq \mathrm{p})$. Eigenvalues quantify the amount of variability explained by each PC, and an eigenvalue greater than one is commonly used as a cut-off point for which PCs are retained. The first PC explains the maximum amount of total variability in the data, the second PC the next largest amount, and so on. For each observation, PC scores are the derived composite scores computed based on the eigenvectors for each PC. PC loadings are correlation coefficients between the PC scores and the original variables, which ranges from -1 to 1 . Therefore, the result of a PCA can eliminate multi-collinearity existed among original variables in multiple regression analysis, and these PC scores can be used in subsequent analyses. The basic model structure for PCA is shown in equation (1).

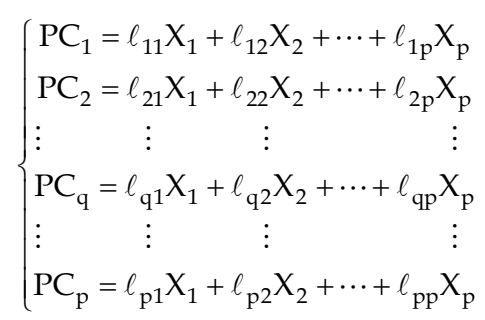

where $\mathrm{X}_{1}, \mathrm{X}_{2}, \cdots, \mathrm{X}_{\mathrm{p}}$ are the original variables; $\mathrm{PC}_{1}, \mathrm{PC}_{2}, \cdots, \mathrm{PC}_{\mathrm{p}}$ are new variables, namely the principal components; $\ell_{\mathrm{ij}}$ is the correlation coefficient between the original variable $j\left(X_{j}\right)$ and principal component $i\left(P_{i}\right)$, namely the PC loading. In this study, PC loadings greater than 0.75 in absolute value as strong correlation, were used to make decisions regarding significant loadings (Liu et al., 2003).

\subsection{Moran-based autocorrelation statistics}

The spatial autocorrelation exists when a value observed in one geographic location depends on the values at neighbouring locations. The spatial autocorrelation coefficient for one geographic location is similar to the traditional Pearson correlation coefficient. In this study, two different scales were applied in spatial autocorrelation analysis. The Moran index (Moran's I), a measure of spatial autocorrelation at global scale, which is used to estimate the magnitude of spatial association among all locations within the study area. The Moran's I statistic, the most common, is defined as following equation (2) (Moran, 1950). The global Moran's I only identify whether an overall spatial clustering propensity exists in a study area. Therefore, Anseline (1995) developed measure of spatial autocorrelation at local scale. The local Moran index (Moran's $\boldsymbol{I}_{i}$ ), which provide the possible contribution of each location to the global Moran's I, is so called as local indicator of spatial association (LISA) (Anselin, 1995). The equation (3) is used to calculate the local Moran's $\boldsymbol{I}_{\boldsymbol{i}}$ statistic. The LISA statistic is a spatial clustering method, which is used to identify significant local homogeneous (hot spots) or heterogeneous (cold spots) regions. The global Moran's $I$ is the weighted average 
of local Moran's $\boldsymbol{I}_{i}$. The null hypothesis $\left(\mathrm{H}_{0}\right)$ of the spatial autocorrelation test is that a variable value of interest is not associated with among neighbouring locations, while the alternative hypothesis $\left(\mathrm{H}_{\mathrm{a}}\right)$ is that the neighbouring locations have similar variable values of interest. The null hypothesis is rejected if the significance test means there is spatial autocorrelation.

$$
\begin{gathered}
I=\frac{\mathrm{n}}{\sum_{\mathrm{i}=1}^{\mathrm{n}}\left(\mathrm{x}_{\mathrm{i}}-\overline{\mathrm{x}}\right)^{2}} \times \frac{\sum_{\mathrm{i}=1}^{\mathrm{n}} \sum_{\mathrm{j}=1}^{\mathrm{n}} \mathrm{w}_{\mathrm{ij}}\left(\mathrm{x}_{\mathrm{i}}-\overline{\mathrm{x}}\right)\left(\mathrm{x}_{\mathrm{j}}-\overline{\mathrm{x}}\right)}{\sum_{\mathrm{i}=1}^{\mathrm{n}} \sum_{\mathrm{j}=1}^{\mathrm{n}} \mathrm{w}_{\mathrm{ij}}}, \mathrm{i} \neq \mathrm{j} \\
I_{i}=\frac{\mathrm{x}_{\mathrm{i}}-\overline{\mathrm{x}}}{\sum_{\mathrm{i}=1}^{\mathrm{n}}\left(\mathrm{x}_{\mathrm{i}}-\overline{\mathrm{x}}\right)^{2}} \times \sum_{\mathrm{j}=1}^{\mathrm{n}} \mathrm{w}_{\mathrm{ij}}\left(\mathrm{x}_{\mathrm{i}}-\overline{\mathrm{x}}\right)\left(\mathrm{x}_{\mathrm{j}}-\overline{\mathrm{x}}\right), \quad \mathrm{i} \neq \mathrm{j}
\end{gathered}
$$

where $n$ is the number of regions in the study; $x_{i}$ and $x_{j}$ are the values of the variable of interest at regions $i$ and $j$, respectively; $w_{i j}$ is an element of an $(n \times n)$ binary spatial weight matrix, $\mathbf{W}$, defining the connection between regions $i$ and $j$ (e.g. 1 represents these two regions are adjacent and 0 for otherwise); $\mathbf{W}$ often is a row-standardized weight means that each row of the weight matrix must sum to one. Moran's I statistic ranges from 1 to 1 , and it equals 0 when there is no spatial autocorrelation. Positive values of Moran's $I$ statistics suggest spatial clustering, while negative values suggest dispersion, that is, high values are frequently found in the vicinity of low values.

In addition, the Moran scatter-plot and a local version of the Moran's I statistic for each region, which are valuable for gaining insights into the extent and nature of spatial clustering in a dataset (Anselin, 1996). The Moran scatter-plot is divided into four quadrants which all denote different levels of spatial association for each individual observation. The upper right quadrant of the Moran scatter-plot indicates regions with above average value share boundaries with neighbouring regions (High-High), i.e. hot spots. The lower left quadrant indicates regions with below average value on the variable of interest share boundaries with neighbouring regions (Low-Low), i.e. cold spots. The lower right quadrant indicates regions with above average values surrounded by regions with below average values (High-Low), and the upper right quadrant is opposite to the front (Low-High). The Moran scatter-plot values can be easily mapped and then further to explore where and how the spatial autocorrelation is located.

\subsection{Spatial regression analysis}

Many studies frequently focus on determining the correlation between potential environmental risk factors and diseases of concern through using multivariate linear regression analyses (Ashley, 1969; Dyomin et al., 1994). However, for analysis of observational data with spatial dependence, the classical linear regression model with spatial auto-correlated residuals violates the independence assumption for error. Spatial dependence effects must be incorporated into the specification of regression model and then the regression model must be estimated using appropriate estimation methods, such as maximum likelihood estimation method. The spatial lag model (SLM) regression can incorporate spatial dependence into the classical regression model (Anselin, 1988). Under 
SLM specification, spatial autocorrelation in the dependent variable derives from exogenous influences. The SLM thus adds an additional predictor in the form of a spatially lagged exogenous variable to explain spatial dependence. A SLM commonly is expressed as equation (4) (Anselin, 1994):

$$
y=\rho \mathbf{W y}+\mathbf{X} \beta+\varepsilon
$$

where $y$ is a $(n \times 1)$ vector of observation on the dependent variable; $\mathbf{X}$ is a $(n \times k)$ matrix representing the $(\mathrm{k}-1)$ explanatory variables and 1 s column to accommodate the constant term; $\beta$ is a $(k \times 1)$ vector of regression coefficient to be estimated; $\rho$ is a spatial autoregressive coefficient of spatial lag term; $\mathbf{W}$ is a spatial weight matrix defining the adjacent relation; $\varepsilon$ is a $(n \times 1)$ vector of random error term. The SLM parameters are estimated using the maximum likelihood method.

The exploratory spatial data analyses and spatial regression were carried out using a clusterdetection software programme of GeoDa version 0.9.5-I, developed by Luc Anselin. For statistical inference, the significance was tested using a Monte Carlo test with 999 permutations at a significance level of 0.05 .

\section{Results and discussion}

\subsection{Principal component analysis for heavy metal in soil}

This study conducted PCA to determine the major PCs influencing the pattern of soil heavy metal pollution in Taiwan.

\begin{tabular}{cccc}
\hline Variables & PC1 & PC2 & PC3 \\
\hline $\mathrm{As}$ & -0.26 & 0.26 & $\mathbf{0 . 8 9}$ \\
$\mathrm{Cd}$ & 0.22 & $\mathbf{0 . 8 5}$ & -0.05 \\
$\mathrm{Cr}$ & $\mathbf{0 . 8 8}$ & -0.12 & -0.01 \\
$\mathrm{Cu}$ & $\mathbf{0 . 8 6}$ & -0.17 & -0.04 \\
$\mathrm{Hg}$ & 0.53 & 0.04 & 0.27 \\
$\mathrm{Ni}$ & $\mathbf{0 . 8 3}$ & -0.18 & 0.25 \\
$\mathrm{~Pb}$ & 0.49 & 0.63 & -0.06 \\
$\mathrm{Zn}$ & $\mathbf{0 . 9 3}$ & -0.05 & -0.08 \\
\hline Eigenvalue & 3.71 & 1.26 & 1.01 \\
\% Total variance & 46.42 & 15.80 & 12.63 \\
Cumulative \% variance & 46.42 & 62.22 & $74.85^{\mathrm{a}}$ \\
\hline
\end{tabular}

a Total cumulative variance. The loading whose absolute value is greater than 0.75 of the total variance were in bold.

Table 4. Results from the principal component analysis (PCA) for heavy metals in soil. 
Three PCs were extracted based on eigenvalues greater than one. These three PCs accounted for $74.85 \%$ of the total variance. Table 4 gives the results of PC loadings, eigenvalues, and cumulative percentage of variation explained by each of these retained three PCs after rotation. In practice, only PC loadings with absolute values greater than 0.75 were selected for the PC interpretation. Using this criterion, the first principal component (PC1) explained $46.42 \%$ of total variance with strong positive loadings on heavy metals $\mathrm{Cr}, \mathrm{Cu}, \mathrm{Ni}$ and $\mathrm{Zn}$. The association of $\mathrm{Cr}, \mathrm{Cu}, \mathrm{Ni}$ and $\mathrm{Zn}$ in $\mathrm{PC1}$ reflects the maximum influence of electroplating and other metal treatment plants on soil pollution Taiwan (Chang et al., 1997). The second principal component (PC2) included heavy metal $\mathrm{Cd}$, which accounted for $15.80 \%$ of the total variance. Heavy metal $\mathrm{Cd}$ was dominated by PC2, which reflects the influence of pigments and plastic factories on soil pollution. The third principal component (PC3) included As, which accounted for $12.63 \%$ of the total variance. In Taiwan, according to previous studies, the As content in soil is closely related to the geologic parent materials (Chang et al., 1999). These three PCs were used to replace the original variables (i.e. eight kinds of heavy metals) to represent overall soil pollution by heavy metals in Taiwan. Additionally, PC scores were the derived composite scores computed for each township based on the eigenvectors for each PC, and they were used in subsequent analyses.

\subsection{Correlation analysis of the explored variables}

Correlation analysis is used as preliminary data analysis before applying more sophisticated techniques. A Pearson's correlation matrix is often used to explore for pairs of variables more likely to be associated. The Pearson's correlation matrix among male oral cancer mortality in different periods, male prevalence rates of BQC and CS, proportion of male aboriginal population as well as principle components PC1, PC2 and PC3 is constructed in Table 5.

\begin{tabular}{lrrrrr}
\hline Variables & $\begin{array}{r}\text { Mortality } \\
(1972-1981)\end{array}$ & $\begin{array}{r}\text { Mortality } \\
(1982-1991)\end{array}$ & $\begin{array}{r}\text { Mortality } \\
(1992-2001)\end{array}$ & $\begin{array}{r}\text { Mortality } \\
(2001-2009)\end{array}$ & Aborigines \\
\hline BQC & $* * 0.17$ & $* * 0.16$ & $* * 0.21$ & $* * 0.30$ & $* 0.12$ \\
CS & -0.07 & -0.03 & -0.03 & 0.00 & $* 0.15$ \\
Aborigines & -0.01 & 0.00 & -0.01 & 0.01 & \\
PC1 & $* * 0.22$ & $* * 0.29$ & $* * 0.26$ & $* * 0.18$ & \\
PC2 & 0.06 & 0.05 & 0.03 & -0.05 & \\
PC3 & $* * 0.24$ & $* * 0.19$ & $* * 0.31$ & $* * 0.38$ & \\
\hline
\end{tabular}

“Mortality (1)-(4)" indicate oral cancer mortality rates in males. "BQC and CS" indicate the male prevalence rate of betel quid chewing and cigarette smoking, respectively $(\mathrm{n}=301)$. "Aborigines" is used to denote the average proportion of the male aboriginal population $(n=349)$. Three extractable principal components of PC1, PC2 and PC3 were determined by principal component analysis applied to eight heavy metals data $(\mathrm{n}=274)$.

* denotes significance at 0.05 ; ${ }^{* *}$ denotes significance at 0.01 .

Table 5. Pearson's correlation matrix among oral cancer mortality in male and related potential factors. 
There was a positive and statistically significant correlation between proportion of aboriginal population and prevalence rates of BQC and CS, which implied BQC is actually a common habit in Taiwanese aborigines. As to the correlations among male oral cancer mortality and these other explored variables, prevalence rate of BQC, proportion of aboriginal population, and principle components PC1 and PC3 were found to be positively correlated with male oral cancer mortality ( $\mathrm{p}$-values $<0.05)$. These findings further validated the correlation between oral cancer and $\mathrm{BQC}$, and indicated that soil heavy metal pollution is possibly related to oral cancer. Conversely, prevalence rate of CS, proportion of aboriginal population, and principle components PC2 had no statistically significant correlation with male oral cancer mortality ( $\mathrm{p}$-values $>0.05$ ). Although CS is highly prevalent for Taiwanese, there is no apparent difference in geographical distribution of CS prevalence.

\subsection{Global spatial autocorrelation of the explored variables}

This study constructed a contiguity-based spatial weight for each township by queen contiguity relationships, which defines spatial neighbours as areas with a shared border and vertexes (Lai et al., 2009). The results of the global Moran's I analyses are summarized in Table 6 . Table 6 shows the positive and statistically significant spatial autocorrelation for male oral cancer mortality in each period. In addition, there was a gradually increasing trend in the degree of spatial autocorrelation for oral cancer mortality, with ranges of global Moran's I values varying from 0.3701 to 0.6201 in the period of nearly forty years. The geographical distribution of aborigines across Taiwan exhibited a significantly positive spatial autocorrelation. There were also positive spatial autocorrelations in the geographical distributions of BQC and CS prevalence rates, and the Moran's I value in prevalence rate of $\mathrm{BQC}$ was greater than that of CS. Additionally, the geographical distributions of all these three PCs representing soil pollution by heavy metals in Taiwan had spatial autocorrelation. Among these three PCs, PC3 with the greatest positive Moran's I value displayed the strongest degree of spatial distribution.

\begin{tabular}{lc}
\hline Variables & Moran's I \\
\hline Mortality (1972-1981) & ${ }^{* *} 0.3701$ \\
Mortality (1982-1991) & ${ }^{* *} 0.4134$ \\
Mortality (1992-2001) & ${ }^{* *} 0.5906$ \\
Mortality (2001-2009) & ${ }^{* *} 0.6201$ \\
Aborigines & $* * 0.5729$ \\
BQC & ${ }^{* *} 0.5726$ \\
CS & $* * 0.3752$ \\
PC1 & $* * 0.5859$ \\
PC2 & $* * 0.1865$ \\
PC3 & $* * 0.7782$ \\
\hline
\end{tabular}

** denotes significance at 0.01 .

Table 6. Global Moran's I of oral cancer mortality in male and related potential factors. 


\subsection{Local spatial clustering}

The use of local indicator of spatial association (LISA) was to identify and explore the patterns of spatial clustering for each selected variable.

\subsubsection{Spatial clusters of oral cancer mortality}

Fig. 2 displays a map showing the distribution of high and low oral cancer mortality rates for male in the three 10-year periods from 1972 to 2001 and during the period of 2001 to 2009. Over the period of 1972 to 1981, a small number of clusters with high oral cancer mortality rate (i.e. hot spots) were observed, mainly located in the central and southernmost regions of Taiwan; the low-mortality clusters of male oral cancer (i.e. cold spots) were discovered in northern part of Taiwan. There was only an unusually apparent highmortality cluster of male oral cancer centred on Changhua and Yunlin Counties of central Taiwan during 1982-1991; however, the high-mortality cluster located in southernmost Taiwan as in the previous time period of was disappeared. From 1992 to 2001, two distinctly large-ranges of high-mortality clusters were identified; one cluster was located in Taitung County of eastern Taiwan besides the previous cluster in central Taiwan. Over the past thirty years, the location and size of high-mortality cluster of male oral cancer in central Taiwan gradually expanded to include the entire Changhua County since 1972. As shown in the lower right figure of Fig. 2, the spatial clustering of male oral cancer mortality from 2001 to 2009 is identified. Although the main high-mortality clusters of male oral cancer in this period of time was slightly different from that in the last period of time, the main two hot spots were also exhibited in central and eastern regions of Taiwan, and cold spots were predominantly located in northern Taiwan.

\subsubsection{Spatial clusters of related potential factors}

The spatial clusters of high proportion of aborigines and high prevalence rates of $\mathrm{BQC}$ and CS for male are indentified are sequentially shown in the Fig. 3 above. The aboriginal population mostly resided in the eastern part of Taiwan, similarly, where one continuous and large-scale cluster with high proportion of aborigines was located. On the contrary, a cold spot of low proportion of aborigines distributed throughout the southwest and midwest Taiwan. For maps of prevalence rates of BQC and CS, an obvious cluster of high BQC prevalence rates was mainly in Taitung and Hualien Counties in eastern Taiwan, while the cluster position of high prevalence rates for CS extended from the northwest to the east.

The spatial clusters of each PC representing soil pollution by heavy metal are presented as Fig. 3 below. Clustering map for PC1, the spatial clusters of high PC1 scores mainly concentrated in the adjacent areas of Taichung and Changhua Counties in central Taiwan. There were five small and fragmented clusters of high PC2 scores spread from north to south throughout Taiwan except for the east. Three more apparent clusters of high PC3 scores were primarily focused on the southwest.

From the above results, the aggregation size of high-mortality rates of male oral cancer not only expanded with time, but also much more strongly clustered. However, the main gathering locations of aboriginal people and high BQC and CS prevalence rates for male were not totally consistent with that of high-mortality rates of oral cancer. Eastern Taiwan of 


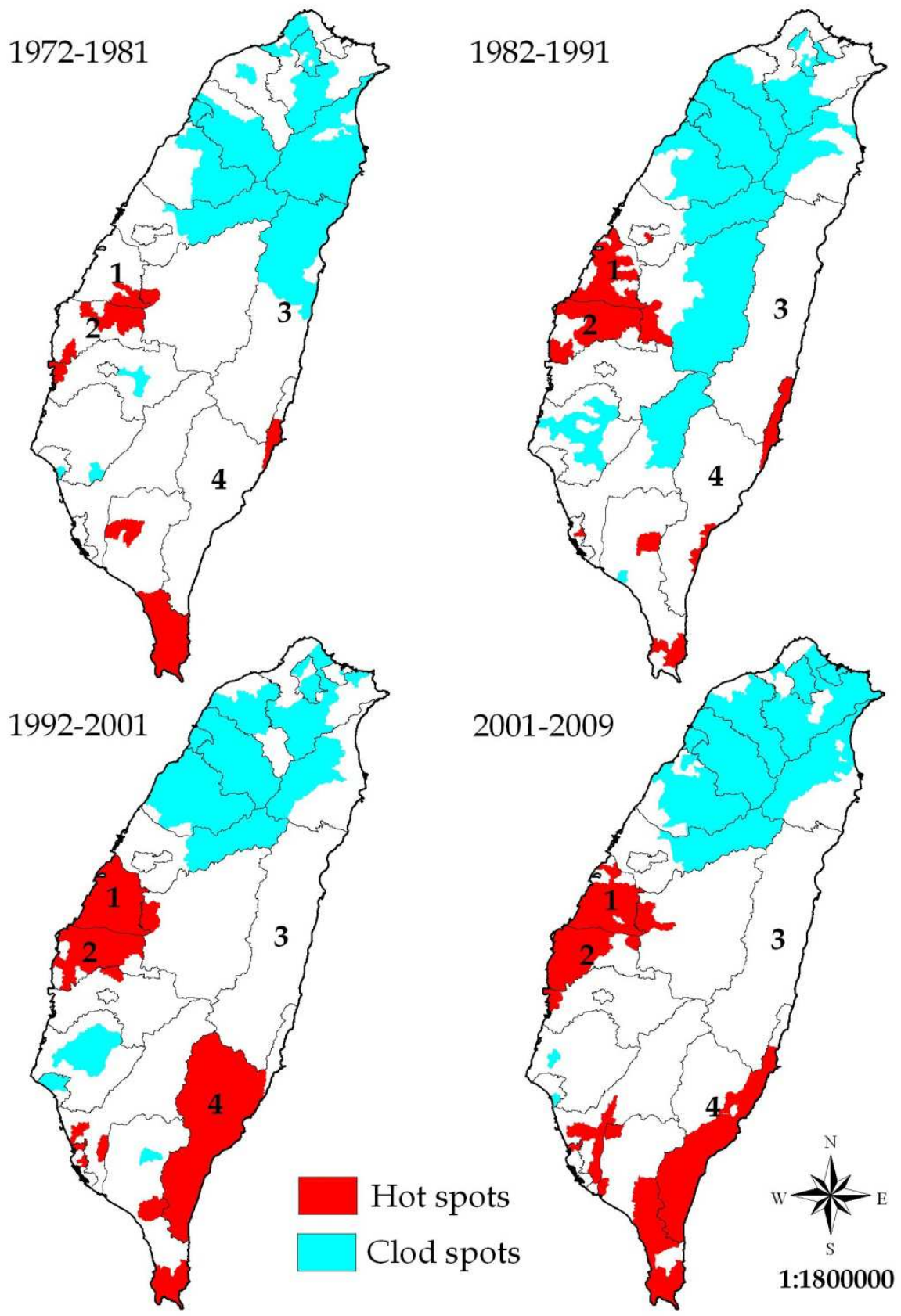

Fig. 2. Cluster locations of oral cancer mortality in males identified by local indicator of spatial association (LISA). 1) Changhua County, 2) Yunlin County, 3) Hualien County, 4) Taitung County. 


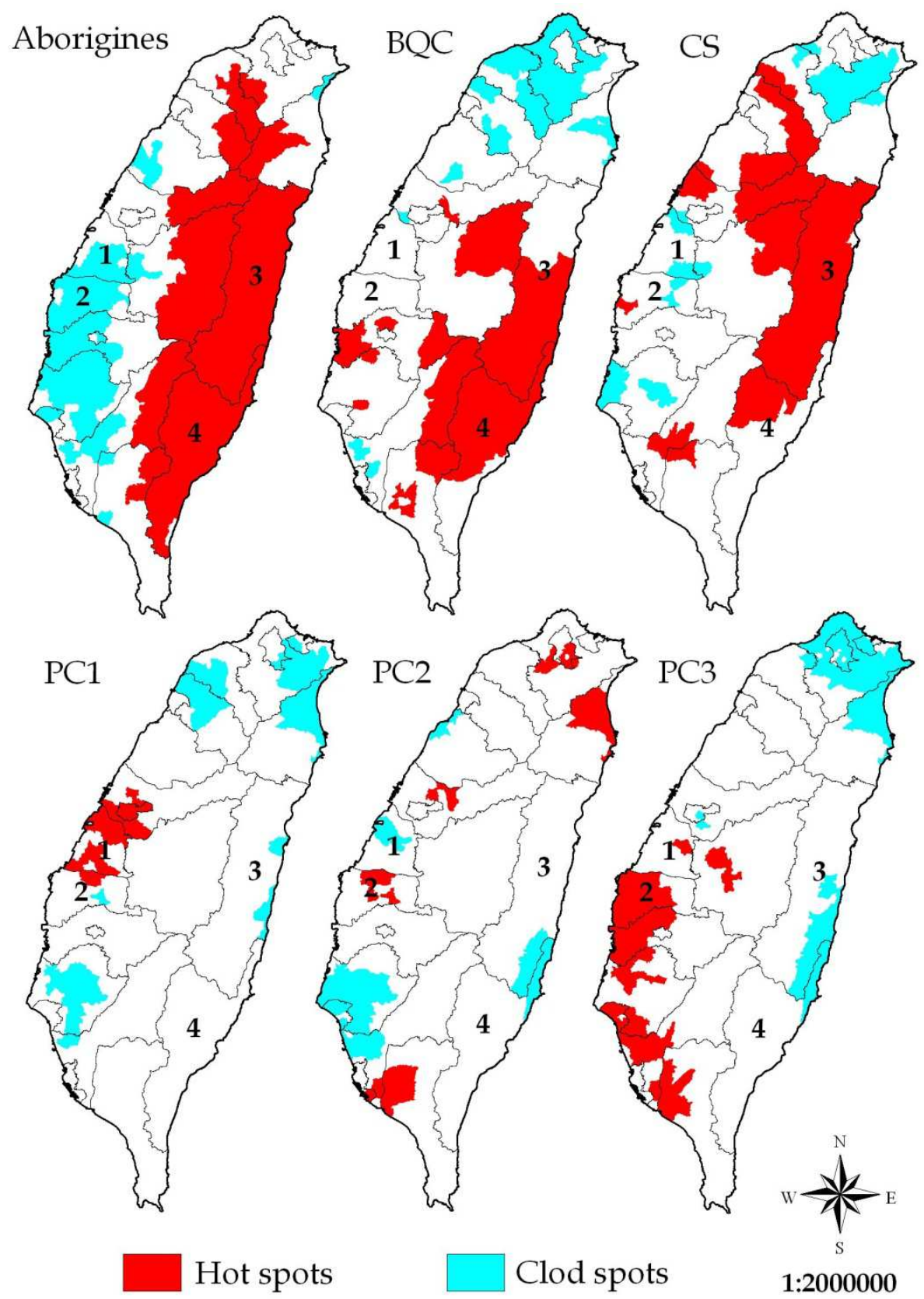

Fig. 3. Cluster locations of related potential factors identified by local indicator of spatial association (LISA). 1) Changhua County, 2) Yunlin County, 3) Hualien County, 4) Taitung County. 
a hot spot for oral cancer can be approximately attributed to where the large numbers of aboriginal people reside and has high prevalence of BQC. But another hot spot for oral cancer is identified in central Taiwan, which is not the main distribution area of aboriginal people and BQC is not seem to be quite prevalent. Since the 1970s, the Taiwan government's policy was to promote "home into small factories," which has caused Changhua County to become a gathering place for electroplating and hardware manufacturing factories. Changhua County, located in central Taiwan, is a well-known Taiwanese "rice warehouse," and more than $60 \%$ of the county's total area has become arable land since 2001 (Council of Agriculture [COA], 2001). During the past few decades, farm soil has been seriously polluted by heavy-metal-contaminated wastewater discharged from factories through irrigation systems in Changhua County (Lin et al., 2002). Therefore, heavy metal pollution was to be considered as a potential risk factor for oral cancer, and three PCs obtained from the PCA were used to represent the overall soil pollution by heavy metals in Taiwan. The locations of hot spots for high PC1 and PC3 scores partially overlapped with a hot spot for oral cancer located in central counties of Taiwan. These findings legitimately suggested that soil pollution by heavy metal is an additional risk factor for oral cancer development.

\subsection{Spatial regression analysis (SLM) for oral cancer mortality rates}

This study further determined whether there is any correlation between the abnormally high-mortality rates of male oral cancer and related potential factors. Based on the results of above Sections 3.2 and 3.3, BQC prevalence rate, PC1 and PC3 had spatial autocorrelation and they correlated with oral cancer mortality. Thus, these three variables were included as predictors in a multiple regression model. The spatial autocorrelation in residuals for ordinary least squares (OLS) regression was found by the Moran's I statistic. Moreover, Lagrange multipliers (LM) and Robust LM for spatial lag were both statistically significant in favor of conducting SLM regression. Table 7 shows the estimation results of non-spatial and SLM regressions for male oral cancer mortality rates in four time periods. For non-spatial regression, PC1, PC3 and BQC prevalence rate significantly and positively spatially associated with oral cancer mortality rates for male in each period of time. In terms of SLM regression, a significantly spatial correlation between PC1 and male oral cancer mortality in the study period except the time period of 2001-2009. Only in the time period of 1992-2001, BQC prevalence rate associated with male oral cancer mortality. The estimation of all four SLM models had significantly positive values for spatial effect. In addition, the percentages of variance explained $\left(\mathrm{R}^{2}\right)$ by the SLM models were greater than that in the non-spatial regressions, indicating that spatial regression model was successful in accounting for spatial correlation in male oral cancer mortality rates.

BQC prevalence rates did not fully spatially correlated with oral cancer mortality rates in spatial regressions, but there was always a significant correlation between them in non-spatial regressions. It does not contradict that $\mathrm{BQC}$ is still the key culprit for causing oral cancer. The spatial regression results indicated that higher PC1 or PC3 scores in areas had higher male oral cancer mortality rates. The association between heavy metal pollution and oral cancer in Taiwan was further determined through regression analyses. Based on these highlights, environmental factors are strongly suspected to promote or cause oral cancer in Taiwan. 


\begin{tabular}{|c|c|c|c|c|c|c|c|c|}
\hline \multirow{3}{*}{ Variables } & \multicolumn{4}{|c|}{ Non-spatial regression } & \multirow{2}{*}{\multicolumn{4}{|c|}{$\begin{array}{l}\text { Spatial lag model regression } \\
\text { Regression coefficients }\end{array}$}} \\
\hline & \multicolumn{4}{|c|}{ Regression coefficients } & & & & \\
\hline & $\begin{array}{r}\text { Mortality } \\
(1972-1981)\end{array}$ & $\begin{array}{r}\text { Mortality } \\
(1982-1991)\end{array}$ & $\begin{array}{r}\text { Mortality } \\
(1992-2001)\end{array}$ & $\begin{array}{r}\text { Mortality } \\
(2001-2009)\end{array}$ & $\begin{array}{r}\text { Mortality } \\
(1972-1981)\end{array}$ & $\begin{array}{r}\text { Mortality } \\
(1982-1991)\end{array}$ & $\begin{array}{r}\text { Mortality } \\
(1992-2001)\end{array}$ & $\begin{array}{r}\text { Mortality } \\
(2001-2009)\end{array}$ \\
\hline constant & $* * 2.661$ & $* * 3.461$ & $* * 7.511$ & **11.921 & $* * 1.216$ & $* * 1.320$ & $* * 2.171$ & $* * 2.903$ \\
\hline PC1 & $* * 0.651$ & **0.902 & **1.406 & $* * 1.613$ & ${ }^{*} 0.289$ & $* * 0.412$ & ${ }^{*} 0.436$ & 0.435 \\
\hline PC3 & $* * 0.576$ & *0.412 & $* * 1.252$ & $* * 2.177$ & 0.195 & 0.135 & *0.426 & *0.605 \\
\hline BQC & ${ }^{*} 0.033$ & $* * 0.044$ & $* * 0.090$ & $* * 0.207$ & 0.010 & 0.017 & 0.022 & $* * 0.063$ \\
\hline Rho $(\rho)$ & - & - & - & - & **0.596 & ${ }^{* *} 0.632$ & ** 0.730 & $* * 0.745$ \\
\hline $\mathrm{R}^{2}$ & 0.115 & 0.149 & 0.210 & 0.278 & 0.356 & 0.438 & 0.609 & 0.646 \\
\hline
\end{tabular}

Rho $(\rho)$ denotes the spatial autoregressive coefficients. $R^{2}$ (the percentage of variation explained) is not directly provided for spatial model and model fit is thus assessed with a pseudo- $\mathrm{R}^{2}$ value calculated as the squared Pearson correlation between predicted and observed values (Kissling \& Carl, 2008).

* denotes significance at 0.05 ;* denotes significance at 0.01 .

Table 7. Regression analysis of oral cancer mortality rates in males and related potential factors.

\section{Conclusion}

In conclusion, by displaying the various data on maps, we found that the hot spots for male mortality rate of oral cancer partially overlapped with that for heavy metal pollution. Additionally, the male mortality rate of oral cancer is geographically associated with heavy metal pollution by conducting spatial regression analyses. In addition to the most wellknown causative etiology of oral cancer, BQC, heavy metal pollution in the environment may be a promoting factor causing the development of oral cancer in Taiwan. Certain heavy metals are currently considered as known human carcinogens. Previous researches have uncovered a critical association between the abnormally high incidence or mortality rates for common types of cancer and the high content of soil heavy metals in the specified regions. Moreover, some epidemiological studies also have suggested that exposure to high levels of specific heavy metals in environmental media may be responsible for the high levels of that in human blood, urine and hair (Chang, Wang, Wang et al., 2006; Chang, Wang, Huang et al., 2006; Chiang et al., 2010; Rosas et al., 1989). More recently a case-control study on oral cancer and non-oral cancer patients living in central Taiwan has found that oral cancer patients' blood levels of heavy metal $\mathrm{Cr}, \mathrm{Ni}, \mathrm{Cu}$ and $\mathrm{Zn}$ were statistically significantly higher than those of non-oral cancer patients (Yuan et al., 2011); furthermore, these heavy metals are the same with the major components of PC1 influencing heavy metal pollution in Taiwan soil, which further indicates a tight link between heavy metal pollution in the environment and oral cancer. Obviously, spatial analysis is a relatively new and potentially valuable tool and it is believed that such techniques will gradually become an integral component of epidemiological research and risk assessment for oral cancer. Finally and most importantly, this study looks forward to providing a new direction in novel researches and issues in related fields such as clinical medicine and epidemiology in the future.

\section{Acknowledgment}

The authors are very grateful to the Department of Health (DOH), Executive Yuan, R.O.C (Taiwan) for providing the cancer registry database for the analyses and two anonymous reviewers for their valuable comments on an earlier draft of this paper. 


\section{References}

Anselin, L. (1988). Spatial Econometrics: Methods and Models (Studies in Operational Regional Science), Springer, ISBN 978-902-4737-35-2, Dordrecht, Boston

Anselin, L. (1995). Local Indicators of Spatial Association-LISA. Geographical Analysis, Vol. 27, No. 2, pp. 93-115, ISSN 1538-4632

Anselin, L. (1996). The Moran Scatterplot as an ESDA Tool to Assess Local Instability in Spatial Association, In: Spatial Analytical Perspectives on GIS: GISDATA 4. M. Fisher; H.J. Scholten \& D. Unwin, (Eds), 111-125, Taylor \& Francis, ISBN 978-0-7484-0339-4, London, UK

Anselin, L. \& Rey, S. (1994). Properties of Tests for Spatial Dependence in Linear Regression Models. Geographical Analysis, Vol. 23, No. 2, pp. 112-131, ISSN 1538-4632

Ashley, D. (1969). Environmental Factors in the Aetiology of Gastric Cancer. British Journal of Preventive \& Social Medicine, Vol. 23, No. 3, pp. 187-189, ISSN 0007-1242

NCI \& NIEHS. (2003). Cancer and the Environment-What You Need to Know. What You Can Do, In: National Cancer Institute (NCI) and National Institute of Environmental Health Sciences (NIEHS), 25.05.2011, Available from http://www.k4health.org/system/files/Cancer\%20_Enviornment.pdf

Blot, W.; McLaughlin, J.; Winn, D.; Austin, D.; Greenberg, R.; Preston-Martin, S.; Bernstein, L.; Schoenberg, J.; Stemhagen, A. \& Fraumeni, J. (1988). Smoking and Drinking in Relation to Oral and Pharyngeal Cancer. Cancer Research, Vol. 48, No. 11, pp. 32823287, ISSN 0008-5472

Cancela, M.; Ramadas, K.; Fayette, J.; Thomas, G.; Muwonge, R.; Chapuis, F.; Thara, S.; Sankaranarayanan, R. \& Sauvaget, C. (2009). Alcohol Intake and Oral Cavity Cancer Risk among Men in a Prospective Study in Kerala, India. Community Dentistry and Oral Epidemiology, Vol. 37, No. 4, pp. 342-349, ISSN 1600-0528

Chang, F.; Wang, H.; Wang, S.; Wang, Y.; Hsieh, D.; Chang, L. \& Ko, Y. (2006). Survey of Urinary Nickel in Residents of Areas with a High Density of Electroplating Factories. Chemosphere, Vol. 65, No. 10, pp. 1723-1730, ISSN 0045-6535

Chang, F.; Wang, S.; Huang, Y.; Tsai, M.; Yu, S. \& Chang, L. (2006). Biomonitoring of Chromium for Residents of Areas with a High Density of Electroplating Factories. Journal of Exposure Analysis and Environmental Epidemiology, Vol. 16, No. 2, pp. 138146, ISSN 1559-0631

Chang, T.; Hwang, K. \& Shyu, G. (1997). Using Factor analysis to Evaluate Characteristic of Metals in Soil Pollution. Journal of Chinese Agricultural Engineering, Vol. 43, pp. 1118, ISSN 0257-5744 (in Chinese)

Chang, T.; Shyu, G.; Lin, Y. \& Chang, N. (1999). Geostatistical, Analysis of Soil Arsenic Content in Taiwan. Journal of Environmental Science and Health Part a-Toxic/Hazardous Substances E Environmental Engineering, Vol. 34, No. 7, pp. 1485-1501, ISSN 10934529

Chiang, C.; Hwang, Y.; Su, C.; Tsai, K.; Lian, I.; Yuan, T. \& Chang, T. (2010). Elucidating the Underlying Causes of Oral Cancer through Spatial Clustering in High-risk Areas of Taiwan with a Distinct Gender Ratio of Incidence. Geospatial Health, Vol. 4, No. 2, pp. 230-242, ISSN 1970-7096

Choi, S. \& Kahyo, H. (1991). Effect of Cigarette Smoking and Alcohol Consumption in the Aetiology of Cancer of the Oral Cavity, Pharynx and Larynx. International Journal of Epidemiology, Vol. 20, No. 4, pp. 878-885, ISSN 0300-5771 
COA. (2001). Agricultural Statistics Yearbook 2001, In: Council of Agriculture (COA), Executive Yuan, R.O.C. (Taiwan), 10.05.2011, Available from

http://www.coa.gov.tw/view.php?catid=209

BHP. (2011a). Cancer Registry Annual Report of the Republic of China (Taiwan), 1995-2008, In: Bureau of Health Promotion (BHP), Department of Health, R.O.C. (Taiwan), 10.05.2011, Available from

http://www.bhp.doh.gov.tw/BHPnet/Portal/Statistics.aspx

BHP. (2011b). Interactive Query System for Cancer Registry, In: Bureau of Health Promotion (BHP), Department of Health, R.O.C. (Taiwan), 15.05.2011, Available from https://cris.bhp.doh.gov.tw/

BHP. (2011c). Interactive Query System for Health Indicators, In: Bureau of Health Promotion (BHP), Department of Health, R.O.C. (Taiwan), 16.05.2011, Available from http:/ / olap.bhp.doh.gov.tw/

Dyomin, S.; Buldacov, L.; Ternovsky, I.; Tokarskaya, Z.; Fomina, T.; Tretyakov, F.; Ivanova, G.; Shevchenko, V.; Kolmogortsev, V. \& Uralshin, A. (1994). Factors Effecting the Morbidity in Populations Living in the Vicinity of Atomic Industry Plants. Science of the Total Environment, Vol. 142, No. 1-2, pp. 105-109, ISSN 0048-9697

Green, C.; Hoppa, R.; Young, T. \& Blanchard, J. (2003). Geographic Analysis of Diabetes Prevalence in an Urban Area. Social Science \& Medicine, Vol. 57, No. 3, pp. 551-560, ISSN 0277-9536

Hotelling, H. (1933). Analysis of Complex Statistical Variables into Principal Components. Journal of Educational Psychology, Vol. 24, No. 6, pp. 417-441, ISSN 0022-0663

IARC. (1987). Overall Evaluations of Carcinogenicity: An Updating of IARC Monographs, In: IARC Monographs on the Evaluation of Carcinogenic Risks to Humans, Volumes 1 to 42 (Supplement 7), World Health Organization International Agency for Research on Cancer, ISBN 978-928-3214-11-3, Lyon, France

IARC. (1988). Alcohol Drinking, In: IARC Monographs on the Evaluation of Carcinogenic Risks to Humans,Volume 44, World Health Organization International Agency for Research on Cancer, ISBN 978-928-3212-44-7, Lyon, France

IARC. (1990). Chromium, Nickel and Welding, In: IARC Monographs on the Evaluation of Carcinogenic Risks to Humans, Volume 49, World Health Organization International Agency for Research on Cancer, ISBN 978-928-3212-49-2, Lyon, France

IARC. (2003). Betel-quid and Areca-nut Chewing and Some Areca-nut-derived Nitrosamines, In: IARC Monographs on the Evaluation of Carcinogenic Risks to Humans, Volume 85, World Health Organization International Agency for Research on Cancer, ISBN 92-832-1285-1, Lyon, France

Kissling, W. \& Carl, G. (2008). Spatial Autocorrelation and the Selection of Simultaneous Autoregressive Models. Global Ecology and Biogeography, Vol. 17, No. 1, pp. 59-71, ISSN 1466-822X

Kitron, U. \& Kazmierczak, J. (1997). Spatial Analysis of the Distribution of Lyme Disease in Wisconsin. American Journal of Epidemiology, Vol. 145, No. 6, pp. 558-566, ISSN $0002-$ 9262

Ko, Y.; Huang, Y.; Lee, C.; Chen, M.; Lin, L. \& Tsai, C. (1995). Betel Quid Chewing, Cigarette Smoking and Alcohol Consumption Related to Oral Cancer in Taiwan. Journal of Oral Pathology \& Medicine, Vol. 24, No. 10, pp. 450-453, ISSN 0904-2512 
Lai, P.; So, F. \& Chan, K. (2009). Areal Methods of Disease Analysis. In Spatial Epidemiological Approaches in Disease Mapping and Analysis, pp. 71-79, Taylor \& Francis, ISBN 978-14200-4546-8, Boca Raton, FL

Lin, C.; Shiau, T.; Ko, Y.; Chen, P. \& Wang, J. (2008). Prevalence and Determinants of Biochemical Dysfunction of the Liver in Atayal Aboriginal Community of Taiwan: Is Betel Nut Chewing a Risk Factor? BMC Gastroenterology, Vol. 8, pp. 1-8, ISSN 1471-230X

Lin, Y.; Teng, T. \& Chang, T. (2002). Multivariate Analysis of Soil Heavy Metal Pollution and landscape Pattern in Changhua County in Taiwan. Landscape and Urban Planning, Vol. 62, No. 1, pp. 19-35, ISSN 0169-2046

Liu, C.; Lin, K. \& Kuo, Y. (2003). Application of Factor Analysis in the Assessment of Groundwater Quality in a Blackfoot Disease Area in Taiwan. The Science of the Total Environment, Vol. 313, No. 1-3, pp. 77-89, ISSN 0048-9697

Merletti, F.; Boffetta, P.; Ciccone, G.; Mashberg, A. \& Terracini, B. (1989). Role of Tobacco and Alcoholic Beverages in the Etiology of Cancer of the Oral Cavity/Oropharynx in Torino, Italy. Cancer Research, Vol. 49, No. 17, pp. 4919-4924, ISSN 0008-5472

Moran, P. (1950). Notes on Continuous Stochastic Phenomena. Biometrika, Vol. 37, No. 1-2, pp. 17-23, ISSN 0006-3444

Ogden, G. (2005). Alcohol and Oral Cancer. Alcohol, Vol. 35, No. 3, pp. 169-173, ISSN 07418329

Pearson, K. (1901). On Lines and Planes of Closest Fit to Systems of Points in Space. Philosophical Magazine, Vol. 2, pp. 559-572, ISSN 1941-5982

Petti, S. \& Scully, C. (2005). Oral Cancer: The Association between Nation-based Alcoholdrinking Profiles and Oral Cancer Mortality. Oral Oncology, Vol. 41, No. 8, pp. 828834, ISSN 1368-8375

Pfeiffer, D.; Minh, P.; Martin, V.; Epprecht, M. \& Otte, M. (2007). An Analysis of the Spatial and Temporal Patterns of Highly Pathogenic Avian Influenza Occurrence in Vietnam Using National Surveillance Data. The Veterinary Journal, Vol. 174, No. 2, pp. 302-309, ISSN 1090-0233

Reichart, P. \& Way, T. (2006). Oral Cancer and Pre-cancer in Myanmar: A Short Review. Journal of Oral Pathology \& Medicine, Vol. 35, No. 4, pp. 193-196, ISSN 0904-2512

Rheeder, J.; Marasas, W.; Farina, M.; Thompson, G. \& Nelson, P. (1994). Soil Fertility Factors in Relation to Oesophageal Cancer Risk Areas in Transkei, Southern Africa. European Journal of Cancer Prevention, Vol. 3, No. 1, pp. 49-56, ISSN 0959-8278

ROCEPA. (1985). Survey of Heavy Metals in the Soil Samples, In: Yearbook of Environmental Protection Statistics Taiwan Area, the Republic of China, Environmental Protection Administration, Executive Yuan, R.O.C. (Taiwan), Taipei

Rosas, I.; Belmont, R.; Baez, A. \& Villalobos-Pietrini, R. (1989). Some Aspects of the Environmental Exposure to Chromium Residues in Mexico. Water, Air, \& Soil Pollution, Vol. 48, No. 3-4, pp. 463-475, ISSN 0049-6979

Stocks, P. \& Davies, R. (1964). Zinc and Copper Content of Soils Associated with the Incidence of Cancer of the Stomach and Other Organs. British Journal of Cancer, Vol. 18, pp. 14-24, ISSN 0007-0920

Su, C.; Yang, H.; Huang, S. \& Lian, I. (2007). Distinctive Features of Oral Cancer in Changhua County: High incidence, Buccal Mucosa Preponderance, and a Close 
Relation to Betel Quid Chewing Habit. Journal of the Formosan Medical Association, Vol. 106, No. 3, pp. 225-233, ISSN 0929-6646

Türkdoğan, M.; Kilicel, F.; Kara, K.; Tuncer, I. \& Uygan, I. (2003). Heavy Metals in Soil, Vegetables and Fruits in the Endemic Upper Gastrointestinal Cancer Region of Turkey. Environmental Toxicology and Pharmacology, Vol. 13, No. 3, pp. 175-179, ISSN 1382-6689

Ward, M. \& Carpenter, T. (2000). Techniques for Analysis of Disease Clustering in Space and in Time in Veterinary Epidemiology. Preventive Veterinary Medicine, Vol. 45, No. 3-4, pp. 257-284, ISSN 0167-5877

Wen, C.; Tsai, S.; Cheng, T.; Chen, C.; Levy, D.; Yang, H. \& Eriksen, M. (2005). Uncovering the Relation between Betel Quid Chewing and Cigarette Smoking in Taiwan. Tobacco Control, Vol. 14, pp. I16-I22, ISSN 0964-4563

Yang, Y.; Chen, H.; Tseng, C. \& Shieh, T. (2002). Prevalence Rates of Areca/Betel Quid Chewing in Counties of Taiwan. Taiwan journal of Oral Medicine Health $\mathcal{E}$ Health Science, Vol. 18, pp. 1-16, ISSN 1560-1587 (in Chinese)

Yuan, T.; Lian I.; Tsai, K.; Chang, T.; Chiang, C.; Su, C. \& Hwang, Y. (2011). Possible Association between Nickel and Chromium and Oal cancer: A Case-control Study in Central Taiwan. Science of the Total Environment, Vol. 409, No. 6, pp. 1046-1052, ISSN 1879-1026

Zeng, D.; Yan, O. \& Li, S. (2008). Spatial Regression-based Environmental Analysis in Infectious Disease Informatics, In: Biosurveillance and Biosecurity, D. Zeng; H.C. Chen; H. Rolka; B. Lober \& M. Waterman, (Eds.), 175-181, Springer-Verlag, ISBN 978-354-0897-45-3, Berlin, Heidelberg 


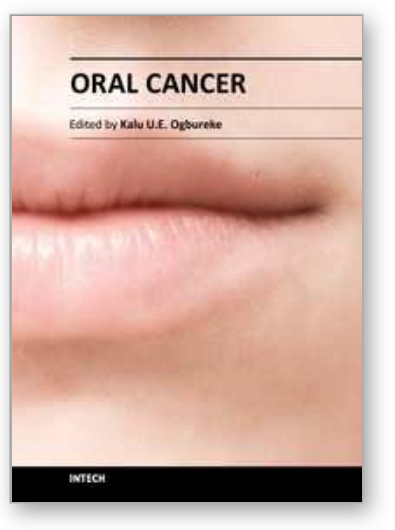

\author{
Oral Cancer \\ Edited by Dr. Kalu U. E. Ogbureke
}

ISBN 978-953-51-0228-1

Hard cover, 388 pages

Publisher InTech

Published online 14, March, 2012

Published in print edition March, 2012

Oral cancer is a significant public health challenge globally. Although the oral cavity is easily accessible, early diagnosis remains slow compared to the enhanced detection of cancers of the breast, colon, prostate, and melanoma. As a result, the mortality rate from oral cancer for the past four decades has remained high at over $50 \%$ in spite of advances in treatment modalities. This contrasts with considerable decrease in mortality rates for cancers of the breast, colon, prostate, and melanoma during the same period. This book attempts to provide a reference-friendly update on the etiologic/risk factors, current clinical diagnostic tools, management philosophies, molecular biomarkers, and progression indicators of oral cancer.

\title{
How to reference
}

In order to correctly reference this scholarly work, feel free to copy and paste the following:

Chi-Ting Chiang, Tsun-Kuo Chang, le-Bin Lian, Che-Chun Su, Kuo-Yang Tsai and Yaw-Huei Hwang (2012). Environmental Factors Identified in the Etiology of Oral Cancers in Taiwan, Oral Cancer, Dr. Kalu U. E. Ogbureke (Ed.), ISBN: 978-953-51-0228-1, InTech, Available from: http://www.intechopen.com/books/oralcancer/environmental-factors-identified-in-the-etiology-of-oral-cancers-in-taiwan

\section{INTECH}

open science | open minds

\section{InTech Europe}

University Campus STeP Ri Slavka Krautzeka 83/A 51000 Rijeka, Croatia Phone: +385 (51) 770447

Fax: +385 (51) 686166 www.intechopen.com

\section{InTech China}

Unit 405, Office Block, Hotel Equatorial Shanghai No.65, Yan An Road (West), Shanghai, 200040, China 中国上海市延安西路65号上海国际贵都大饭店办公楼 405 单元 Phone: +86-21-62489820

Fax: $+86-21-62489821$ 
(C) 2012 The Author(s). Licensee IntechOpen. This is an open access article distributed under the terms of the Creative Commons Attribution 3.0 License, which permits unrestricted use, distribution, and reproduction in any medium, provided the original work is properly cited. 